\title{
INVESTIGAÇÃO DOS MÉTODOS PARA AVALIAÇÃO DA EXPOSIÇÃO DE PROFESSORES E AUXILIARES DE CLASSE DA EDUCAÇÃO ESPECIAL A FATORES DE RISCO DISTÚRBIOS OSTEOMUSCULARES
}

\section{RESEARCH OF METHODS FOR ASSESMENT OF EXPOSURE OF TEACHERS AND CLASS AUXILIARY OF SPECIAL EDUCATION TO MUSCULOSKELETAL DISORDERS RISK FACTORS}

\author{
Felipe Adriano Wojcikiewicz ${ }^{1}$ \\ Elton Moura Nickel ${ }^{2}$, D. Sc. \\ Flávio Anthero Nunes Vianna dos Santos ${ }^{3}$, D. Sc. \\ (1) Universidade do Estado de Santa Catarina - UDESC \\ e-mail: lipewcz@gmail.com \\ (2) Universidade do Estado de Santa Catarina - UDESC \\ e-mail: eltonnickel@gmail.com \\ (3) Universidade do Estado de Santa Catarina - UDESC \\ e-mail: flavioanvs@hotmail.com
}

Métodos, educação especial, distúrbios osteomusculares

Levantamento exploratório acerca da aplicabilidade de ferramentas de avaliação de fatores de risco de distúrbios osteomusculares relacionados ao trabalho de docentes e auxiliares da educação especial, fundamentado em pesquisas sobre a prevalência dos distúrbios na educação regular e a ocorrência das ferramentas utilizadas para avaliação da sintomatologia osteomuscular.

Methods, special education, musculoskeletal disorders

Exploratory survey about the applicability of tools for the assessment of risk factors for musculoskeletal disorders related to the work of teachers and class assistants in special education, based on research on the prevalence of disorders in regular education and the occurrence of the tools used to evaluate musculoskeletal symptoms.

\section{Introdução}

O trabalho é fundamental na vida de homens e mulheres; contudo, quando realizado de maneira inadequada, pode transformar-se em fator prejudicial à saúde humana. Alguns grupos de trabalhadores, por suas características ocupacionais, tornam-se mais expostos ao surgimento de distúrbios osteomusculares relacionados ao trabalho (DORT). E dentre estes grupos, destacam-se os profissionais da educação.

Por vezes, o trabalho desses profissionais é exercido sob circunstâncias desfavoráveis, as quais os docentes mobilizam suas capacidades físicas, cognitivas e afetivas para atingir os objetivos da produção escolar, gerando com isso sobre-esforço
Realização:

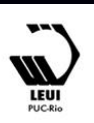




\section{$16^{\circ}$ \\ ERGODESIGN USIHC CINAHPA}

ou hipersolicitação de suas funções

psicofisiológicas. Ou seja, o trabalho docente é uma atividade que promove estresse, com repercussões sobre a saúde física e mental e com impactos no desempenho profissional.

Assim como em muitos outros países, o Brasil trabalha pela construção de um sistema educacional inclusivo. Porém nos últimos anos, o setor educacional vem sofrendo mudanças, que estão ocasionando na intensificação das atividades docentes ao mesmo tempo em que aponta na direção da precarização das relações de trabalho. Cortes nos recursos financeiros destinados à educação são reflexos de novos processos de organização social e as instituições escolares passaram a enfrentar novos obstáculos devido às diferentes realidades culturais e sociais ao buscar cumprir adequada e satisfatoriamente seus compromissos educacionais.

É o caso da educação especial onde, além das atividades pedagógicas, os educadores estão mais expostos ao sobre-esforço físico, a depender do tipo de deficiência dos alunos e dadas às circunstâncias onde se faz necessária a movimentação de alunos e/ou o posicionamento postural de acordo com o dispositivo assistivo necessário ao desempenho da atividade. Mesmo que feito com ajuda de auxiliares de sala.

\section{Bases Conceituais}

No Brasil, pouco ainda tem sido feito para avaliar a repercussão do trabalho sobre a saúde em categorias de trabalhadores em que os fatores de risco são menos visíveis, como por exemplo, os professores. Sobretudo na educação especial, onde o problema é ainda mais complexo, uma vez que não só é pouco avaliada a repercussão do trabalho sobre a saúde de educadores, assim como trabalhos de pesquisa constituem uma temática quase que marginal, dada à escassez na produção nessa área. Assim, o embasamento teórico dessa pesquisa buscou investigar quais ferramentas podem vir a ser mais aplicáveis na avaliação dos fatores de risco relacionados ao trabalho de docentes da educação especial, através de uma revisão de sobre a aplicação de ferramentas de avaliação de risco $16^{\circ}$ Ergodesign - Congresso Internacional de Ergonomia e Usabilidade de Interfaces Humano Tecnológica: Produto, Informações Ambientes Construídos e Transporte

$16^{\circ}$ USIHC - Congresso Internacional de Ergonomia e Usabilidade de Interfaces Humano Computador

CINAHPA | 2017 - Congresso Internacional de Ambientes Hipermídia para Aprendizagem. ergonômico na educação regular, visando encontrar alternativas melhor exequíveis, que viabilizem uma reflexão sobre práticas profissionais e a possibilidade de incorporar um novo olhar e uma nova práxis à educação especial.

\subsection{O contexto da educação especial}

Educação especial e educação inclusiva são termos que normalmente se confundem com "escolas especiais" e escolas que atendem alunos "de inclusão". E apesar de estarem intimamente ligados, os termos assumem características diferentes: "educação inclusiva está relacionada ao acesso na classe convencional da rede regular de ensino para todas as pessoas, independentemente de cor, etnia, sexo, idade e/ou necessidades especiais" (MENDES, 2002), ao passo que educação especial assume o papel de organizar os meios necessários para desenvolver os potenciais das pessoas com necessidades especiais, seja em escolas especializadas ou não. "A educação especial assume o caráter de escola paralela, mas como um conjunto de medidas que a escola regular dispõe para o atendimento das necessidades especiais dos alunos" (OLIVEIRA; GLAT, 2003).

Quando se refere à formação do educador, seja ele docente ou auxiliar, é preciso compreender como está sendo preparado esse profissional: quais suas atribuições, suas exigências, como são tratados pelas políticas públicas educacionais. Diversas ações, políticas públicas, educacionais e administrativas vem sendo implantadas e reformuladas ao longo da história, no intuito de promover a educação inclusiva em diversos contextos. A Lei de Diretrizes e Bases da Educação no 9.394 de 1996, afirma em seu Artigo 59 que os sistemas de ensino devam assegurar aos alunos "currículos, métodos, técnicas, recursos e organização específicos, para atender às suas necessidades", assim como "professores com especialização adequada em nível médio ou superior, para atendimento especializado" (BRASIL, 1996).

Nesse contexto, o educador passa também a acumular a função de intermediador de recursos e dispositivos que possibilitem aos alunos desempenhar suas capacidades. Juntamente com 


\section{$16^{\circ}$ \\ ERGODESIGN USIHC CINAHPA}

o(s) auxiliar(es) de sala, o docente passa a ter a função de organizar e proporcionar ao aluno a forma adequada de se posicionar e utilizar os dispositivos disponíveis para que este possa desempenhar de forma plena suas capacidades ao realizar tarefas. Sendo, dessa forma, necessária a adequada formação dos educadores para que possam proporcionar o uso adequado, eliminando possíveis fatores de risco osteomusculares que venham a incidir tanto sobre educadores, quanto sobre alunos.

Diante desta transformação histórico-social da qual as escolas fazem parte, ao mesmo tempo a inclusão promove incertezas na equipe escolar, que precisa atentar a adquirir novas habilidades para poder atuar nesse novo contexto. Hoje os cursos de formação de docentes já vêm sendo repensados e se adequando às novas legislações do sistema educacional, como a Resolução CNE/CP nº1/2002, que institui Diretrizes Curriculares Nacionais para a Formação de Professores da Educação Básica, determinando que caiba às instituições de ensino superior "prever em sua organização curricular formação docente voltada para a atenção à adversidade" e que os projetos políticopedagógicos devem contemplar conteúdos curriculares com "conhecimento sobre as especificidades dos alunos com dificuldades educacionais especiais" (BRASIL. 2002).

Porém, conforme HUMMEL (2015) ainda assim os cursos propostos não contemplam conhecimentos suficientes para que os futuros docentes sejam capazes de trabalhar com a inclusão de alunos com deficiência. Geralmente é destinada apenas uma disciplina sobre o tema nesses cursos.

Ainda de acordo com HUMMEL (2015), a formação de educadores deve se voltar para a compreensão de que o ambiente escolar constituise por indivíduos heterogêneos, sendo, portanto, de extrema importância que os educadores saibam determinar as especificidades dos alunos com necessidades especiais para que se possa identificar e compreender as características das deficiências. Dessa forma, torna-se necessária a capacitação através de atividades contextualizadas e ações práticas que favoreçam o desenvolvimento de $16^{\circ}$ Ergodesign - Congresso Internacional de Ergonomia e Usabilidade de Interfaces Humano Tecnológica: Produto, Informações Ambientes Construídos e Transporte

$16^{\circ}$ USIHC - Congresso Internacional de Ergonomia e Usabilidade de Interfaces Humano Computador

CINAHPA | 2017 - Congresso Internacional de Ambientes Hipermídia para Aprendizagem.

habilidades e competências ao futuro educador.

\subsection{A Necessidade de Ferramentas para Avaliação de Distúrbios Osteomusculares Relacionados ao Trabalho (DORT)}

Conforme SANTOS et al. (2009), distúrbios osteomusculares relacionados ao trabalho (DORT), são um conjunto de afecções do aparelho locomotor decorrente de atividades laborais que acometem músculos, fáscias, tendões, articulações e nervos, principalmente dos membros superiores, ombros e cervical resultando em dor fadiga e declínio do desempenho profissional.

Na última década, por demanda do sindicalismo, o trabalho docente tornou-se tema de vários estudos e de investigações, incentivando a formação de grupos e de redes de pesquisadores organizados para esse fim. As condições de trabalho, ou seja, as circunstâncias sob as quais os docentes realizam as atividades se tornaram pano de fundo para o desenvolvimento de estudos a respeito dos fatores de risco aos quais docentes e auxiliares estão expostos. Se fazendo necessário o uso de métodos ou ferramentas de avaliação ocupacional e de fatores de risco ergonômicos, para que se possa analisar a carga de trabalho a que são submetidos, bem como se as atividades estão sendo desempenhadas de maneira adequada, sem que haja tanto o comprometimento no desempenho da atividade, como, principalmente, prejuízo à saúde do docente. Através destes métodos e ferramentas, também é possível se avaliar o impacto da falta de capacitação dos profissionais. Embora o sucesso da educação dependa em boa parte do perfil do docente, a administração escolar, na maioria dos casos, não fornece os meios pedagógicos necessários à realização das tarefas, que são cada vez mais complexas. Os professores são compelidos a buscar, então, por seus próprios meios, formas de requalificação que se traduzem em aumento não reconhecido e não remunerado da jornada de trabalho (TEIXEIRA, 2001; BARRETO e LEHER, 2003; OLIVEIRA, 2003).

É importante que se possa ressaltar que a participação de docentes e auxiliares em todo e qualquer tipo de questionários, métodos avaliativos
Realização:

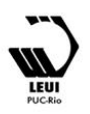




\section{$16^{\circ}$ \\ ERGODESIGN USIHC CINAHPA}

e/ou experimentos de avaliação, mesmo que seja em caráter voluntário, não há a necessidade de identificar-se, assim como recomenda a resolução 196/96 do Conselho Nacional de Saúde, que assegura aos participantes a confidencialidade das informações, sendo estas usadas exclusivamente para atender aos objetivos da pesquisa em questão.

\section{Procedimentos Metodológicos}

É preciso se ter em mente as diferentes características de trabalho entre educadores da educação regular e da educação especial. Docentes e auxiliares de sala da educação especial, além de todas as atividades de ensino, ainda acumulam tarefas como, por exemplo, a movimentação e posicionamento de alunos nos dispositivos assistivos necessários ao desempenho das atividades. Ou seja, os educadores estão sujeitos às posturas de trabalho não previstas e,

consequentemente, expostos a diversas solicitações (sejam elas animadas ou inanimadas), semelhante aos trabalhadores da saúde, quando da movimentação de pacientes. Especialmente pelo fato de alguns dos alunos, em razão das características e especificidades de suas deficiências, serem usuários de andadores, cadeiras de rodas, ou mesmo acamados.

Dessa forma, essa etapa da pesquisa se baseou em um levantamento exploratório da ocorrência de estudos publicados em língua portuguesa, com a temática da aplicação de ferramentas de avaliação de fatores de risco ergonômico em educadores do ensino regular. Assim, permitindo que se possam ser avaliadas essas ferramentas, traçando um paralelo com ferramentas que possam vir a ser melhor aplicáveis na educação especial.

\subsection{Ferramentas para Avaliação de Fatores de Risco de DORT}

Anterior ao desenvolvimento da pesquisa foi feito um levantamento de, pelo menos, quatro ferramentas de avaliação as quais poderiam ser discutidas e adaptadas ao contexto da educação especial. Para isso foi utilizado o recorte da Fundação Catarinense de Educação Especial $16^{\circ}$ Ergodesign - Congresso Internacional de Ergonomia e Usabilidade de Interfaces Humano Tecnológica: Produto, Informações Ambientes Construídos e Transporte

$16^{\circ}$ USIHC - Congresso Internacional de Ergonomia e Usabilidade de Interfaces Humano Computador

CINAHPA | 2017 - Congresso Internacional de Ambientes Hipermídia para Aprendizagem.

(FCEE), onde se pode avaliar na própria instituição algumas das necessidades mais latentes, bem como a ocorrência de diversos fatores de risco no desempenhar das funções de educador, seja docente ou auxiliar de sala.

Partindo das características e das especificidades do atendimento educacional da instituição, foram avaliadas ferramentas que fossem adaptáveis à realidade da própria instituição, de forma simples e com uma boa relação custo-benefício. Dessa forma, foram selecionadas duas ferramentas a serem aplicadas por profissional como: o Rapid Entire Body Assesment (REBA), que é uma ferramenta indicada a avaliar posturas em atividades onde haja cargas dinâmicas e/ou não previstas. A ferramenta avalia o corpo todo e estabelece ao ergonomista cinco níveis de ação para os fatores de risco ergonômico (negligenciável, baixo, médio, alto e muito alto). É o mais indicado e amplamente utilizado na área médica, onde os profissionais dessa área lidam diariamente com movimentação e transferência de pessoas cadeirantes, acamadas ou com mobilidade reduzida, onde, justamente, se encontra a grande possibilidade de adaptá-lo e aplicar à educação especial.

\begin{tabular}{|c|c|c|c|}
\hline $\begin{array}{c}\text { Nível de } \\
\text { ação }\end{array}$ & Pontuação & Nível de risco & Intervenção \\
\hline 0 & 1 & Negligenciável & $\begin{array}{c}\text { Não } \\
\text { necessário }\end{array}$ \\
\hline 1 & $2-3$ & Baixo & $\begin{array}{c}\text { Pode ser } \\
\text { necessário }\end{array}$ \\
\hline 2 & $4-7$ & Médio & \begin{tabular}{c} 
Necessário \\
\hline 3
\end{tabular} \\
\hline $4-10$ & Alto & $\begin{array}{c}\text { Pontualmente } \\
\text { necessário }\end{array}$ \\
\hline 4 & $11-15$ & Muito alto & $\begin{array}{c}\text { Atuação } \\
\text { imediata }\end{array}$ \\
\hline
\end{tabular}

Tabela 1: Níveis de risco e ação REBA

O método PLIBEL é uma ferramenta bastante parecida com o REBA, porém mais simplificado. É aplicada em duas etapas através de um formulário seguido de um questionário que também avalia 


\section{$16^{\circ}$ \\ ERGODESIGN USIHC CINAHPA}

$16^{\circ}$ Ergodesign - Congresso Internacional de Ergonomia e Usabilidade de Interfaces Humano Tecnológica: Produto, Informações Ambientes Construídos e Transporte

$16^{\circ}$ USIHC - Congresso Internacional de Ergonomia e Usabilidade de Interfaces Humano Computador

CINAHPA | 2017 - Congresso Internacional de Ambientes Hipermídia para Aprendizagem. posturas sobre todo o corpo. Em sua aplicação um profissional observa e entrevista o indivíduo pontuando os resultados. O profissional pode ser capacitado através de manual de aplicação disponível.

Ambas as ferramentas não exigem muita capacitação por parte do profissional que irá aplicá-las. Ambas dispõem de guias de fácil compreensão e disponível em domínio livre na internet, assim como os formulários padrão.

As outras ferramentas selecionadas são aplicadas de forma direta aos indivíduos, ou seja, os próprios avaliados se encarregam de fornecer dados e responder os questionários: o Questionário Oesteomuscular Holandês (DMQ) é uma ferramenta onde o indivíduo coleta dados pessoais, dados sobre a rotina de trabalhado, saúde e sobre as atividades que ele desempenha em seu trabalho (quais lhe provocam desconforto, incômodo, dor,). O questionário padrão é composto por nove páginas, mas modelos adaptados compreendem questionários que vão de quatro até vinte páginas, a depender das necessidades de verificação do analista. Sua aplicação pode ser feita em qualquer local (até em casa), podendo ser concluída em cerca de 30 minutos.

E, por fim, o Questionário Nórdico (QNSO) que é o método mais amplamente utilizado e adaptado, de acordo com o levantamento da pesquisa. Tratase do mais simplificado dos métodos, constituído de um questionário rápido com pouco mais de duas páginas, abordando questões como dados pessoais, sobre saúde e sobre rotina de trabalho, da mesma forma como o questionário Holandês, porém de forma mais enxuta e com menos variáveis (a depender da necessidade do analista). A ferramenta avalia, de maneira fácil, desconfortos em todas as regiões do corpo e a frequência que eles ocorrem.

\section{Resultados}

\subsection{Ocorrência do Uso de Ferramentas de Avaliação de DORT na Educação Regular}

No levantamento da pesquisa, pode se observar o amplo uso do Questionário Nórdico (QNSO), seja de forma associada a outros questionários ou mesmo de maneira isolada. CARVALHO e ALEXANDRE (2006) em seu estudo sobre sintomas oesteomusculares em professores do ensino fundamental, pesquisaram 18 escolas estaduais e municipais de uma cidade do interior de SP, avaliando 157 professores ativos dessas escolas. A coleta de dados foi efetuada através de um questionário aplicável em duas partes, sendo a primeira parte sobre dados gerais e ocupacionais. Na primeira parte, o instrumento construído, segundo os autores, foi submetido à validação de seu conteúdo por meio da apreciação de seis juízes com reconhecido saber na temática investigada. Três juízes eram docentes do Departamento de Medicina Preventiva e Social, um do

Departamento de Enfermagem e, uma socióloga do Centro de Pesquisas Materno-Infantil de Campinas (Cemicamp), todos da Universidade Estadual de Campinas (Unicamp) e, também, um docente do Ensino Fundamental da rede estadual. Já a segunda parte foi utilizada a parte geral do QNSO para avaliar os sintomas osteomusculares. $\mathrm{O}$ instrumento utilizado foi uma versão adaptada culturalmente para a língua portuguesa por BARROS e ALEXANDRE (2003).

O estudo utilizou variáveis categóricas como idade, tempo de atuação na profissão, quantidade de alunos por sala, local e quantidade de classes em que leciona, além de variáveis numéricas e avaliação estatística de um período de 12 meses, investigando e comparando indivíduos com ou sem ocorrência de sintomas osteomusculares. E os resultados apresentaram uma elevada ocorrência desses sintomas, demonstrando uma grande procura por auxílio de algum profissional da área da saúde, além da influência na execução das atividades cotidianas, reforçando que os sintomas osteomuculares representam um problema para esta categoria profissional.

Os resultados também mostraram que vários fatores individuais e ocupacionais podem estar relacionados com sintomas osteomusculares nas diferentes regiões corporais. Verificou-se que professores mais novos, que não possuem uma união estável, sem filhos e com um tempo menor 


\section{$16^{\circ}$ \\ ERGODESIGN USIHC CINAHPA}

de atuação profissional estão mais sujeitos ao aparecimento de sintomas osteomusculares.

Da mesma forma, MELO, CAIXETA e CAIXETA (2010) apresentaram um estudo sobre a prevalência de lesões oesteomusculares em professores do ensino fundamental. A avaliação foi realizada com 45 professores ativos em seis escolas da rede municipal de Catalão/GO, no período entre 09 de agosto e 29 de outubro de 2010, onde apresentaram também uma ferramenta de avaliação composta por uma ficha de identificação com dados pessoais do e histórico ocupacional dos indivíduos avaliados e uma versão adaptada do QNSO. Nesse caso, na análise efetuada através do QNSO, a prevalência de dor, formigamento e dormência nos últimos 12 meses, independentemente da região corporal afetada, foi de $100 \%$ entre os professores da rede Municipal de Ensino. As queixas foram predominantes nos ombros $16 \%$ e parte superior das costas $15,3 \%$.

Do total de investigados, $96,3 \%$ responderam que a presença da sintomatologia osteomuscular nos últimos 12 meses impediu a realização das atividades de vida diária, tendo $96 \%$ dos participantes relatado ter realizado consulta a algum profissional da saúde devido ao referido problema. Nesse estudo, os autores ainda sugeriram a utilização de ferramentas complementares, tendo em vista a necessidade de pesquisas mais acuradas a fim de fornecer subsídios para programas de prevenção.

Por sua vez, SANCHEZ et. al.(2013) salientam em seu estudo que, para identificar as possíveis doenças ocupacionais decorrentes de postos de trabalho inadequados, é indicada a utilização do QNSO, propondo unificar a mensuração dos relatos de DORT, facilitando a comparação entre estudos. Dessa forma os autores também utilizaram a versão transcultural adaptada à língua portuguesa por BARROS e ALEXANDRE (2003).

Ressaltando que, através da ferramenta, também se buscou a investigação de outra questão: a percepção dos indivíduos quanto à associação entre sintomas e o exercício da atividade profissional.

FERNANDES, ROCHA e COSTA-OLIVEIRA $16^{\circ}$ Ergodesign - Congresso Internacional de Ergonomia e Usabilidade de Interfaces Humano Tecnológica: Produto, Informações Ambientes Construídos e Transporte

$16^{\circ}$ USIHC - Congresso Internacional de Ergonomia e Usabilidade de Interfaces Humano Computador

CINAHPA | 2017 - Congresso Internacional de Ambientes Hipermídia para Aprendizagem.
(2009), avaliaram 242 professores da rede municipal de ensino em Natal-RN, onde foi aplicado um questionário composto por dois blocos de questões, sendo a primeira parte sobre dados socioeconômicos e a segunda parte correspondendo ao QNSO, a qual, segundo os autores, é muito utilizado devido a sua rápida e econômica aplicação, sendo facilmente validado e adaptado culturalmente à língua portuguesa. E, de acordo com o levantamento referente aos doze meses anteriores à pesquisa, observou-se a prevalência de $93 \%$ de sintomas osteomusculares nos indivíduos investigados, o que salientou a importância da implantação de medidas de prevenção.

JÚNIOR e SILVA (2014) desenvolveram um estudo sobre a sintomatologia de DORT em docentes da Universidade de Pernambuco, Campus Petrolina. Os autores avaliaram uma amostra de 49 indivíduos aplicando questionários socioeconômico, QNSO e o questionário de atividade física, IPAQ, avaliando dados inclusive como a percepção da intensidade da dor. Dessa forma, pode-se inferir que cerca aproximadamente $45 \%$ dos indivíduos são sedentários e que pouco mais de $85 \%$ dos docentes descreveram sentir algum tipo de sintoma osteomuscular (dor, formigamento, desconforto, dormência), sendo que aproximadamente $64 \%$ relatam que os sintomas pioram com a atividade de lecionar. Os autores ainda sugeriram estudos com uma amostragem maior, a fim de que possíveis correlações e associações possam ser evidenciadas, visando fornecer evidências, para uma intervenção global focada na prevenção de lesões e estratégias ergonômicas direcionadas aos movimentos, posturas e toda sobrecarga exigida durante o trabalho, diminuindo assim a prevalência de DORT.

Percebendo-se o vasto uso do QNSO, durante a pesquisa também se observou que, em alguns estudos, foram aplicados questionários de avaliação desenvolvidos e adaptados pelos próprios autores. Além disso, outras ferramentas de avaliação como o questionário de atividade física IPAQ, puderam ser observadas, tendo em vista a necessidade de maior detalhamento sobre a saúde 


\section{$16^{\circ}$ \\ ERGODESIGN USIHC CINAHPA}

física dos indivíduos avaliados, no intuito de se observar correlações entre a possibilidade do indivíduo ter uma vida mais sedentária. O que pode influenciar no aparecimento de DORT, ou até mesmo agravar distúrbios ou sintomas já existentes. O IPAQ é uma ferramenta que se assemelha muito ao questionário holandês DMQ, porém com respostas mais abertas.

LIMA, GOMES e STURMER (2012) no estudo desenvolvido em uma escola pública do noroeste do Rio Grande do Sul, avaliaram a prevalência de DORT através do IPAQ. Foi constituída uma amostra de 15 professores ativos, onde foi possível observar que mesmo relatando algum tipo de dor e/ou desconforto, $40 \%$ dos entrevistados disseram considerar sua saúde muito boa. A avaliação do nível de atividade física apontou que $60 \%$ dos entrevistados são classificados como ativos, $86,6 \%$ apresentam dores em variadas regiões do corpo e aproximadamente $93 \%$ relataram algum tipo de dor referente ao trabalho.

CARDOSO et.al.(2009), realizaram um estudo epidemiológico sobre as condições de trabalho dos professores do ensino fundamental da rede municipal de ensino de Salvador-BA. A ferramenta utilizada era um questionário composto por blocos de questões, muito similar ao questionário holandês DMQ. Inclusive com as respostas podendo ser expressas em escala de frequência do tipo Lickert: $0=$ nunca; $1=$ raramente; $2=$ frequente; 4 = muito frequente. A pesquisa abordou 4.496 dos 4.697 professores da rede (cerca de $95 \%$ ). A pesquisa também relata que muitos dos professores adotam posturas inadequadas, influenciadas principalmente por ambientes com condições inadequadas, o que pode contribuir para o aparecimento das DORT. $16^{\circ}$ Ergodesign - Congresso Internacional de Ergonomia e Usabilidade de Interfaces Humano Tecnológica: Produto, Informações Ambientes Construídos e Transporte

$16^{\circ}$ USIHC - Congresso Internacional de Ergonomia e Usabilidade de Interfaces Humano Computador

CINAHPA | 2017 - Congresso Internacional de Ambientes Hipermídia para Aprendizagem.

\begin{tabular}{|c|c|c|c|c|c|}
\hline Estudo & Localidade & População estudada* & $\begin{array}{c}\text { Áreas } \\
\text { corporais } \\
\text { mais } \\
\text { acometidas }\end{array}$ & Instrumento** & $\begin{array}{l}\text { Delineamento } \\
\text { do estudo }\end{array}$ \\
\hline Carvalho & Interior de SP & $\begin{array}{l}157 \text { Dcs rede mun. e } \\
\text { est. }(99,4 \% \mathrm{M}, 0,6 \% \\
\text { H) }\end{array}$ & $\begin{array}{c}\text { Cervical, } \\
\text { Torácica, } \\
\text { Lombar, } \\
\text { Membros } \\
\text { superiores e } \\
\text { Inferiores }\end{array}$ & $\begin{array}{l}\text { Quest. Des. Aut.+ } \\
\text { QNSO }\end{array}$ & Transversal \\
\hline Melo & Catalāo - GO & $\begin{array}{l}45 \text { Dcs rede mun. } \\
(87 \% \mathrm{M}, 13 \% \mathrm{H})\end{array}$ & $\begin{array}{c}\text { Cervical, } \\
\text { Torácica, } \\
\text { Lombar, } \\
\text { Membros } \\
\text { superiores e } \\
\text { Inferiores }\end{array}$ & $\begin{array}{l}\text { Quest. Des. Aut.+ } \\
\text { QNSO }\end{array}$ & Transversal \\
\hline Cardoso & Salvador-BA & $\begin{array}{l}4.697 \text { Dcs rede mun. } \\
(92 \% \mathrm{M}, 8 \% \mathrm{H})\end{array}$ & $\begin{array}{c}\text { Torácica, } \\
\text { Membros } \\
\text { superiores e } \\
\text { inferiores }\end{array}$ & Quest. Des. Aut. & Transversal \\
\hline Lima & Noroeste-RS & $\begin{array}{l}15 \text { Dcs ens. fund. } \\
(13,3 \% \mathrm{M}, 86,7 \% \mathrm{H})\end{array}$ & $\begin{array}{c}\text { Cervical, } \\
\text { Torácica, } \\
\text { Lombar, } \\
\text { Membros } \\
\text { superiores e } \\
\text { Inferiores }\end{array}$ & $\begin{array}{l}\text { Quest. Des. Aut. } \\
+ \text { IPAQ }\end{array}$ & $\begin{array}{l}\text { Quantitativo } \\
\text { Qualitativo }\end{array}$ \\
\hline Sanchez & Rio Verde-GO & 36 Dcs ens. sup. & $\begin{array}{c}\text { Cervical, } \\
\text { Torácica, } \\
\text { Lombar, } \\
\text { Membros } \\
\text { superiores e } \\
\text { Inferiores }\end{array}$ & QNSO & Transversal \\
\hline Fernandes & Natal-RN & $\begin{array}{l}242 \text { Dcs rede bás. } \\
(81,7 \% \mathrm{M}, 18,3 \% \mathrm{H})\end{array}$ & $\begin{array}{c}\text { Cervical, } \\
\text { Lombar e } \\
\text { Torácica } \\
\end{array}$ & $\begin{array}{l}\text { Quest. Des. Aut. } \\
+ \text { QNSO }\end{array}$ & Transversal \\
\hline Junior & Petrolina-PE & $\begin{array}{l}49 \text { Dcs ens. sup. } \\
(71,4 \% \mathrm{M}, 28,6 \% \mathrm{H})\end{array}$ & $\begin{array}{l}\text { Cervical, } \\
\text { Torácica, } \\
\text { Lombar, } \\
\text { Membros } \\
\text { superiores e } \\
\text { Inferiores }\end{array}$ & $\begin{array}{l}\text { Quest. Des. Aut. } \\
+ \text { IPAQ + QNSO }\end{array}$ & Transversal \\
\hline $\begin{array}{l}* \text { Dcs }=\text { Doc } \\
\text { autores; QN }\end{array}$ & $\begin{array}{l}\text { es; } M=\text { Mulhe } \\
=\text { questionár }\end{array}$ & $\begin{array}{l}\text { s; } \mathrm{H}=\text { Homens; }{ }^{* *} \\
\text { hórdico; IPAQ = que }\end{array}$ & $\begin{array}{l}\text { Pes. Aut. }=\mathrm{q} \\
\text { rio de ativida }\end{array}$ & $\begin{array}{l}\text { questionário deser } \\
\text { ade física }\end{array}$ & Ivido pelos \\
\hline
\end{tabular}

\section{Discussão}

Através da pesquisa pode-se observar a predominância da aplicação da versão de BARROS e ALEXANDRE (2003) do QNSO. Até por suas características de mais fácil acesso à avaliação por parte dos indivíduos, bem como por parte das instituições, devido sua boa relação custo-benefício. Assim como também foi possível observar características muito similares entre os resultados. Dessa forma, o método pode ser tranquilamente adaptável ao contexto da educação especial,

Um fator que chamou a atenção foi o maior percentual de docentes do sexo feminino, aliado ao maior acometimento de distúrbios osteomusculares, seja por exigência da rotina de trabalho, questões fisiológicas e/ou emocionais.

Ao se analisar os fatores de risco de uma forma geral, são avaliados dados pessoais e ocupacionais. E dessa forma se verifica que os resultados podem 


\section{$16^{\circ}$ \\ ERGODESIGN USIHC CINAHPA}

$16^{\circ}$ Ergodesign - Congresso Internacional de Ergonomia e Usabilidade de Interfaces Humano Tecnológica: Produto, Informações Ambientes Construídos e Transporte

$16^{\circ}$ USIHC - Congresso Internacional de Ergonomia e Usabilidade de Interfaces Humano Computador

CINAHPA | 2017 - Congresso Internacional de Ambientes Hipermídia para Aprendizagem. se apresentar até mesmo de forma controversa, principalmente pela decorrência dos fatores serem avaliados por região corporal separadamente. Assim, muitos resultados são difíceis de explicar e podem ser decorrentes do desenho metodológico adotado para este a avaliação. Tais resultados podem ser esperados, uma vez que os sintomas osteomusculares têm origem multifatorial e na situação real de trabalho vários fatores podem estar influenciando sua ocorrência simultaneamente.

Partindo então desse ponto, para poder se desenvolver/adaptar e aplicar uma ferramenta de avaliação para o contexto da educação especial deve-se observar que existe uma série de fatores complicadores da atividade laboral do educador, dada a diferença para a educação regular. Porém, é preciso tomar cuidado na elaboração ou adaptação da ferramenta que virá a ser utilizada. Caso contrário, se não for uma ferramenta bem estruturada e de fácil compreensão pelo indivíduo avaliado (ou pelo especialista que estiver aplicando), corre-se o risco de se trabalhar com uma ferramenta que acabe orientando os resultados, tornando os dados menos fidedignos, podendo estes ser influenciados pela falta de conhecimento.

Nesse contexto, a fisioterapeuta da Fundação Catarinense de Educação Especial (FCEE), Sany Fernandes de Oliveira ressalta que tanto o especialista quanto a instituição que promoverá a aplicação de tal avaliação, devem estar atentos ao fato de não se desconsiderar o nível de formação e o contexto social dos educadores avaliados. Segundo Sany o conhecimento popular (ou o "achismo") pode influenciar negativamente nos resultados, não refletindo a realidade. Daí a importância de ferramentas bem estruturadas e, principalmente de fácil compreensão.

Ao avaliar as ferramentas que possivelmente seriam melhor aplicáveis ao contexto da educação especial, Sany também destaca que ferramentas como o REBA e como o QNSO podem tanto ser aplicadas separadamente como podem constituir processos de avaliação em mais de uma etapa. Principalmente o REBA, por suas características voltadas aos setores da saúde que se assemelham às características de muitas das atividades da educação especial.

A terapeuta ocupacional e professora da Universidade Federal do Paraná, UFPR, Gabriela Cordeiro Correa, M.Sc., sugere que seja aplicada uma versão adaptada à educação especial do questionário holandês DMQ. Segundo Gabriela, das quatro ferramentas elencadas na primeira etapa da pesquisa, esta seria a mais completa e, principalmente, de melhor compreensão tanto por especialistas como por parte dos indivíduos avaliados.

\section{Conclusão}

O desenvolvimento de estudos sobre os fatores de risco de DORT no contexto da educação especial constituem hoje uma temática praticamente inexistente. Esse panorama contribui de maneira que esse seja um tema marginalizado. Em contrapartida, a educação regular constitui um panorama vastamente explorado por especialistas das áreas da ergonomia e da terapia ocupacional. E os resultados da presente pesquisa, mesmo demonstrando a necessidade de novos estudos sobre esta temática dada à escassez de trabalhos na área, ainda assim oferece um ponto de onde partir. Pois é latente a necessidade de dados mais consistentes sobre a avaliação de fatores de risco incidentes na educação especial, sobretudo pelo fato de se buscar viabilizar condições melhores de trabalho para os educadores.

É necessário destacar a relevância da aplicação de ferramentas como o QNSO, visto ser amplamente empregado e adaptado em diversas avaliações.

Uma ferramenta bem planejada, bem elaborada e adaptada às necessidades de um determinado recorte dentro da educação especial, não só permite a identificação de sintomas de distúrbios, ou a avaliação de determinadas posturas de trabalho. Ferramentas corretamente aplicadas permitem inclusive se prever quais ações devem ser tomadas ou ainda, permite o consistente levantamento de requisitos para que se possa oferecer capacitação adequada aos educadores.

\section{Realização: "') UNIVERSIDADE FEDERAL




\section{$16^{\circ}$ \\ ERGODESIGN USIHC CINAHPA}

\section{BIBLIOGRAFIA}

ALEXANDER, D.L. - School Employees: The Forgotten Municipal Workers. Occup Med, v.16, n.1, 65-78, 2001.

BARRETO, R. G.; LEHER, R. - Trabalho docente e as reformas neoliberais. In: OLIVEIRA, D. A. Reformas educacionais na América Latina e os trabalhadores docentes. Belo Horizonte: Autêntica, 2003. p. 39-60.

BARROS, E.N.C., ALEXANDRE, N.M.C. Cross-cultural Adaptation of the Nordic Musculoskeletal Questionnaire. Int Nurs Rev, v.50, n.2: 101-08, 2003.

BRASIL. Conselho Nacional de Educação.

Resolução CNE/CP 1, de 18 de fevereiro de 2002. Institui diretrizes curriculares para a formação de professores da educação básica. Brasília, 2002. Disponível em:

<http://portal.mec.gov.br/seesp/arquivos/pdf/res1_ 2.pdf $>$. Acesso em 15/11/2016.

BRASIL. Lei no 9.394. LDB: Lei de Diretrizes e Bases da Educação Nacional, de 20 de dezembro de 1996. Estabelece as Diretrizes e Bases da educação Nacional. Brasília, 1996. Disponível em: <www.planalto.gov.br/ccivil_03/leis/19394.htm> Acesso em: 17/11/2016.

CARDOSO, J. P.; RIBEIRO, I. Q. B.; ARAÚJO, T. M.; CARVALHO, F. M.; REIS, E. J. F. B. Prevalência de Dor Musculoesquelética em Professores, São Paulo, v.12, n.4, p.604-14, 2009.

CARVALHO, A.J.F.P.; ALEXANDRE, N.M.C. Sintomas Osteomusculares em Professores do Ensino Fundamental, Revista Brasileira de Fisioterapia, São Carlos, v. 10, n. 1, p. 35-41, 2006.

CONTE, Elaine; BASEGIO, Antônio C. Tecnologias Assistivas: Recursos Pedagógicos Para a Inclusão Humana, Revista Temas em Educação, João Pessoa, v.24, n. 2, p. 28-44, jul.dez. 2015. $16^{\circ}$ Ergodesign - Congresso Internacional de Ergonomia e Usabilidade de Interfaces Humano Tecnológica: Produto, Informações Ambientes Construídos e Transporte

$16^{\circ}$ USIHC - Congresso Internacional de Ergonomia e Usabilidade de Interfaces Humano Computador

CINAHPA | 2017 - Congresso Internacional de Ambientes Hipermídia para Aprendizagem.

FERNANDES, M. H.; ROCHA, V. M.; COSTAOLIVEIRA, A. G. R. - Fatores Associados à Prevalência de Sintomas Osteomusculares em Professores, Revista de Salud Pública, Bogota, v.11, n.2, 2009.

HUMMEL, Eromi Izabel. Tecnologia Assistiva: A Inclusão na Prática. $1^{\mathrm{a}}$ Edição, Curitiba: Appris, 2015.

HERRERA, A. R. C. S.; DICKIE, I. B.; SCHULEMBURG, H. R. W. - Design Inclusivo: Interface Gráfica Voltada para Crianças com Síndrome de Down, Ergodesign \& HCI, Rio de Janeiro, v. 2, n. 1, jul. 2014.

JÚNIOR, J. P. L.; SILVA, T. F. A. - Análise da Sintomatologia de Distúrbios Osteomusculares em Docentes da Universidade de Pernambuco Campus Petrolina, Revista Dor, São Paulo, v. 15, n. 4, p.276-280, 2014.

LIMA, R. D. C.; GOMES. M. P.; STURMER, G. Prevalência de Distúrbios Osteomusculares em Professores de Uma Escola Pública no Noroeste do Rio Grande do Sul, EFDeportes, Buenos Aires, n. 170, 2012.

MELO, E. M. N.; CAIXETA, G. F.; CAIXETA, A. - Prevalência de Lesões Osteomusculares em Professores do Ensino Fundamental, Saúde CESUC, Catalão, n. 1, 2010.

MENDES, E. G. - Desafios Atuais na Formação do Professor em Educação Especial. Revista Integração. Brasília, n. 24, ano 14, p.12 - 17, 2002.

TEIXEIRA, L. H. G. - Políticas públicas de educação e mudança nas escolas: um estudo da cultura escolar. In: OLIVEIRA, D. A.; DUARTE, M. R. T. (Orgs.) Política e trabalho na escola: administração dos sistemas de educação básica. 2 . ed., Belo Horizonte, 2001, p. 177-190

OLIVEIRA, D. A. - As reformas educacionais e suas repercussões sobre o trabalho docente. In OLIVEIRA, D. A. - Reformas educacionais na
Realização:

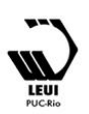


$16^{\circ}$ USIHC - Congresso Internacional de Ergonomia e Usabilidade de CINAHPA

América Latina e os trabalhadores docentes. Autêntica: Belo Horizonte, 2003, p. 13-35.

OLIVEIRA, M. G. - Condições de trabalho, gênero e saúde: Sofrimento e estresse, um estudo de caso com os profissionais docentes do ensino superior privado de Belo Horizonte. Dissertação (Mestrado) - Pontifícia Universidade Católica de Minas Gerais, Belo Horizonte, 2001.

OLIVEIRA, E. da S. G.; GLAT, R. - Educação Inclusiva: Ensino Fundamental para os Portadores de Necessidades Especiais. In: VALLE, B. de B. $\mathrm{R}$. et AL. Fundamentos teóricos e metodológicos do ensino fundamental. Curitiba: Iesde, 2003.

SANCHEZ, H. M.; GUSATTI, N.; SANCHEZ, E. G. M.; BARBOSA, M. A. - Incidência de Dor Musculoesquelética em Docentes do Ensino Superior, Revista Brasileira de Medicina do Trabalho, São Paulo, v.11, n.2, p.66 - 75, 2013. SANTOS, G. L. V.; SILVA, I. L.; CARDOSO, F.; BERESFORD, H. - Ocorrência de Distúrbios Osteomusculares Relacionados ao Trabalho dos Professores de uma Instituição de Ensino Superior de Belém/PA. Fisioterapia Brasil, Rio de Janeiro, 2009, v.10 n.4.

\section{Agradecimentos}

Agradecimentos à Fundação Catarinense de Educação Especial por sempre ser receptiva com seus visitantes, pelo empenho da coordenadora do Centro de Educação e Vivência da FCEE, Rana Medeiros, da fisioterapeuta Sany Oliveira e da professora Gabriela Cordeiro. E também ao professor Flávio Anthero Nunes Vianna dos Santos, ao meu orientador Elton Moura Nickel e aos demais colegas de turma do Programa de PósGraduação em Design da Universidade do Estado de Santa Catarina 